\title{
Chi-Square Test
}

National Cancer Institute

\section{Source}

National Cancer Institute. Chi-Square Test. NCI Thesaurus. Code C53235.

Chi-square test is a statistical test for testing the null hypothesis that the distribution of a discrete random variable coincides with a given distribution. It is one of the most popular goodness-of-fit tests. 